\title{
EFFECT OF LEMON GRASS (CYMBOPOGON CITRATUS) AND ROSELLE (HIBISCUS SABDARIFFA) SUPPLEMENTATION AS ANTIOXIDANT SOURCES IN DIET OF LACTATING EWES.
}

\author{
M.A.M. Abdullah ${ }^{1}$, M.G.M. Bakheet ${ }^{1}$, M.N.M Abd El-Ati1, M. W. Daghash ${ }^{1}$, Asmaa H.M. Moneeb ${ }^{2}$, \\ and Wafaa G. Mahmoud ${ }^{3}$
}

1-Department of Animal Production, Faculty of Agriculture, Assiut University, Assiut, 71526, Egypt, 2- Department of Dairy Science, Faculty of Agriculture, Assiut University, Assiut, 71526, Egypt, 3- Department of Parasitology, Faculty of Vet. Med. New Valley, Assiut University, Assiut, 71526, Egypt

The experiment is carried out to study the effect of Lemon grass and Roselle supplementation as antioxidant sources in diet of lactating ewes. Twenty-eight ewes in the last month of pregnancy, average body weight $45 \pm 2 \mathrm{~kg}$ is assigned to 4 treatments ( 7 ewes of each group) for 75 days ( 15 before parturition and 60 days after parturition) using complete randomized block design. The treatments included: (1) the control ration, consisted of concentrate mixture: wheat straw (60:40 dry matter bases); (2) control ration $+4 \mathrm{~g}$ Lemon grass (Cymbopogon citratus) $/ \mathrm{kg}$ of concentrate mixture (LG); (3) control ration $+4 \mathrm{~g}$ Roselle Lemon grass (Cymbopogon Cymbopogoncitratus)/kg of concentrate mixture (RO); (4) control ration $+2 \mathrm{~g}$ Lemon grass (Cymbopogon citratus) $/ \mathrm{kg}$ of concentrate mixture $+2 \mathrm{~g}$ Roselle (Hibiscus sabdariffa) $/ \mathrm{kg}$ of concentrate mixture (LGRO). Ewes were weighed at the beginning of the experiment and over two weeks to adjust the feed requirements. Feed intake and milk production was recorded daily. Milk samples were taken biweekly for chemical composition. Blood and rumen samples were taken at the end of the experiment. Also, Feces samples were taken at the end of the experiment to analyzed parasitic number (Coccidia number). The addition of LG or RO or LGRO did not affect milk yield or milk composition. In blood plasma there was a significant decrease in albumin concentration in treatment groups compared to the CON group. Also, there was significant increase in ALT, AST concentrations in LGRO compared to the other groups. On the other hand, there was a decrease in creatine level in treatment groups compare to CON group. In rumen samples, the protozoal count was significant high in LG and RO compared to CON and LGRO groups. Also, there was high significant deference in TVFA concentration in LGRO and RO compared to the CON group. Finally, from our findings, we conclude that, addition of herbs plant can be used in dairy ewes without any harmful effect on animal performance. This kind of herbs and at this level, succeed as a natural feed additives to improve animals rumen fermentation under this condition of the experiment.

Keywords: Lemon grass (Cymbopogon cymbopogoncitratus), Roselle (Hibiscus sabdariffa), antioxidant, lactating ewes 